\title{
ASPECTOS GEOMORFOLÓGICOS, PROCESSOS MORFODINÂMICOS E USO E OCUPAÇÃO DAS TERRAS DO MUNICÍPIO DE PEDRINHAS/SERGIPE
}

\author{
Bruna Leidiane Pereira Santana ${ }^{(a)}$; Débora Barbosa da Silva ${ }^{(b)}$; Neise Mare de Souza Alves ${ }^{(\mathrm{c})}$; \\ Ray Santos Andrade ${ }^{(d)}$ \\ a) Mestranda do programa de pós-graduação em Geografia/Universidade Federal de Sergipe, \\ bruna.leydiane@gmail.com \\ (b) Professora adjunta do Departamento de Geografia/ Universidade Federal de Sergipe,deborabarbs@ gmail.com \\ (c) Professora adjunta do Departamento de Geografia/ Universidade Federal de Sergipe, neisemare@ gmail.com \\ (d) Biologia Licenciatura/ Universidade Federal de Sergipe, raybiotanica@ gmail.com
}

Eixo: Uso e ocupação das terras e legislação ambiental

\begin{abstract}
Resumo
A visão integrada da paisagem a partir de suas características físicas possibilita compreender os processos que dinamiza um sistema ambiental, assim como a atuação morfodinâmica subordinada aos aspectos geomorfológicos e potencializada pela ação antrópica representada no espaço rural pelas atividades agrícolas. Nesta perspectiva, caracterizar os aspectos geomorfológicos do município de Pedrinhas/SE, associando-os a atuação dos processos morfodinâmicos e o uso e ocupação das terras pode resultar em um panorama das condições de estabilidade que envolve o relevo e os solos, visto que a relação estabelecida entre ambos condiciona o desenvolvimento da agricultura e da pecuária extensiva na área, contudo, as técnicas de manejo utilizadas não se ajustam as características inerentes a esses componentes desencadeando pontualmente desajustes representados pela ocorrência de feições erosivas.
\end{abstract}

Palavras chave: Processos morfodinâmicos; Uso e ocupação das terras; Aspectos geomorfológicos.

\section{Introdução}

As distintas características do relevo dependem da interação estabelecida entre agentes endógenos e exógenos. A dinâmica de evolução do modelado a partir de forças externas ocorre, principalmente, pelas condições climáticas que atua sobre diferentes litologias permitindo a escultura de feições morfológicas capazes de indicar os processos de formação e sua relação com outros componentes do sistema ambiental e a ação antrópica.

Neste contexto, a ação antrópica representa um agente capaz de intensificar a atuação dos processos morfodinâmicos através do desenvolvimento de atividades produtivas que requerem a supressão da vegetação nativa e ocupação de áreas com maior propensão a instabilidade - encosta e vertentes com declividades acentuadas. 
A distribuição das atividades produtivas nos diferentes compartimentos relevo além de propiciar sua instabilidade, podem desencadear problemas de ordem ambiental e social, como assoreamento de canais fluviais, perda de solos e diminuição do quantitativo da produção agrícola. Assim, o presente trabalho objetiva caracterizar os aspectos geomorfológicos do município de Pedrinhas/SE, associando-os a atuação dos processos morfodinâmicos e o uso e ocupação das terras.

A natureza desse trabalho justifica-se em razão da necessidade de gerar informações que possam subsidiar ações destinadas ao espaço rural na perspectiva de adequar as técnicas de manejo as características dos recursos naturais como o relevo e solos utilizados no desenvolvimento das atividades produtivas, principalmente, quando se considera que a área de estudo tem sua economia alicerçada na agricultura e pecuária extensiva.

\section{Metodologia e procedimentos técnicos}

A metodologia adotada na realização deste trabalho fundamenta-se na análise integrada da paisagem segundo os princípios sistêmicos. Deste modo, para alcançar o objetivo proposto foram definidos os seguintes procedimentos: pesquisa bibliográfica; levantamento e análise dos documentos cartográficos; trabalhos em campo e, confecção de mapas.

A pesquisa bibliográfica foi realizada junto materiais disponíveis nos acervos virtuais de instituições e bibliotecas na perspectiva de aprofundar o conhecimento acerca do objeto de estudo e levantar informações relevantes para o trabalho.

Foram consultados e analisados os seguintes produtos cartográficos mapas temáticos - geologia, geomorfologia, vegetação, recursos hídricos, etc. - escala 1:1.000.000 do Projeto RADAMBRASIL (BRASIL,1983); Mapa Exploratório - Reconhecimento de Solos do Estado de Sergipe município de Pedrinhas, escala 1:500.000 (EMBRAPA, 1973); Mapa Geológico do Estado de Sergipe, escala 1:250.000 (SANTOS et al., 1998). A obtenção destas informações secundárias foram utilizadas na caracterização do sistema ambiental e na confecção dos mapas.

Os trabalhos de campo possibilitaram a obtenção de informações primárias sobre as feições de modelado, sua distribuição e organização na paisagem, bem como sobre uso e ocupação das terras e processos morfodinâmico do município de Pedrinhas.

Para a produção dos mapas temáticos foi utilizado ao software ArcGis 10.1. Os dados referentes ao mapa das unidade geomorfológicas tiveram como referência o mapa geomorfolófico do RADAMBRASIL (BRASIL,1983) e o mapeamento da dissecação foi estabelecida a partir da observação de campo. 
As informações sobre a declividade foram obtidas a partir de imagens SRTM (Shuttle Radar Topography Mission) TOPODATA e a utilização das ferramentas Arctoolbox - Spatial Analyst Tools - Surface - Slope. Enquanto o mapa hipsométrico foi gerado através do Arctoolbox - 3D Analyst Tools - TIN - Create TIN.

O mapeamento do uso das terras correu através da utilização de satélite do Landsat 8 sensor TIRS 2015 associada as observações de campo e as instruções do Manual Técnico de Uso da Terra (IBGE, 2006). O procedimento para classificação se iniciou com a composição das bandas 1- red, 2- green, e 3- blue, seguida da interpretação visual diretamente na tela do computador, utilizando elementos básicos de interpretação, como cor, textura, forma, tonalidade, tamanho, sombra, padrão, adjacências e localização geográfica.

\section{Caracterização ambiental e aspectos geomorfológicos da área de estudo}

O município de Pedrinhas possui uma área de 33,9 Km² (IBGE, 2010) e aproximadamente $94 \mathrm{~km}$ de distâcia da capital sergipana, tendo a sede como coordenadas geográficas $-11^{\circ} 19^{\prime} 65^{\prime}$ ' de latitude Sul e 3767’36" de longitude Oeste. A área de estudo abrange oTerritório Sul Sergipano, limitando-se ao norte com o município de Boquim, a leste e sul com o Arauá, a oeste e sul com Itabaianinha.

Em relação as condições climáticas o município encontram-se inserido numa área onde as temperatura média anual é de $24,1^{\circ}$. O regime pluviométrico é marcado por um período seco que compreende os meses de outubro a fevereiro com precipitações mensais que geralmente estão abaixo de $100 \mathrm{~mm}$ e outro úmido que ocorre entre os meses de abril a setembro, quando os totais pluviométricos são mais elevados que os demais meses do ano (EMDAGRO, 2009). Essas características possibilitaram o domínio da Floresta Estacional Semidecidual na área como formação vegetal predominante, representada atualmente, por poucos fragmentos isolados de espécies arbóreas e arbustivas.

De acordo com os estudos de compartimentação geomorfológica realizados por Brasil (1983), o município de Pedrinhas se insere em dois domínios morfoestruturais Bacias e Coberturas Sedimentares e Depósitos Sedimentares. O domínio das Bacias e Coberturas Sedimentares é constituído pela região do Baixo Planalto Palmares-Estância e unidade geomorfológica dos Tabuleiros do Rio Real. Enquanto as Coberturas Sedimentares abrange a região dos Piemontes Inumados representados pelos Tabuleiros Costeiros (Figura 1). 

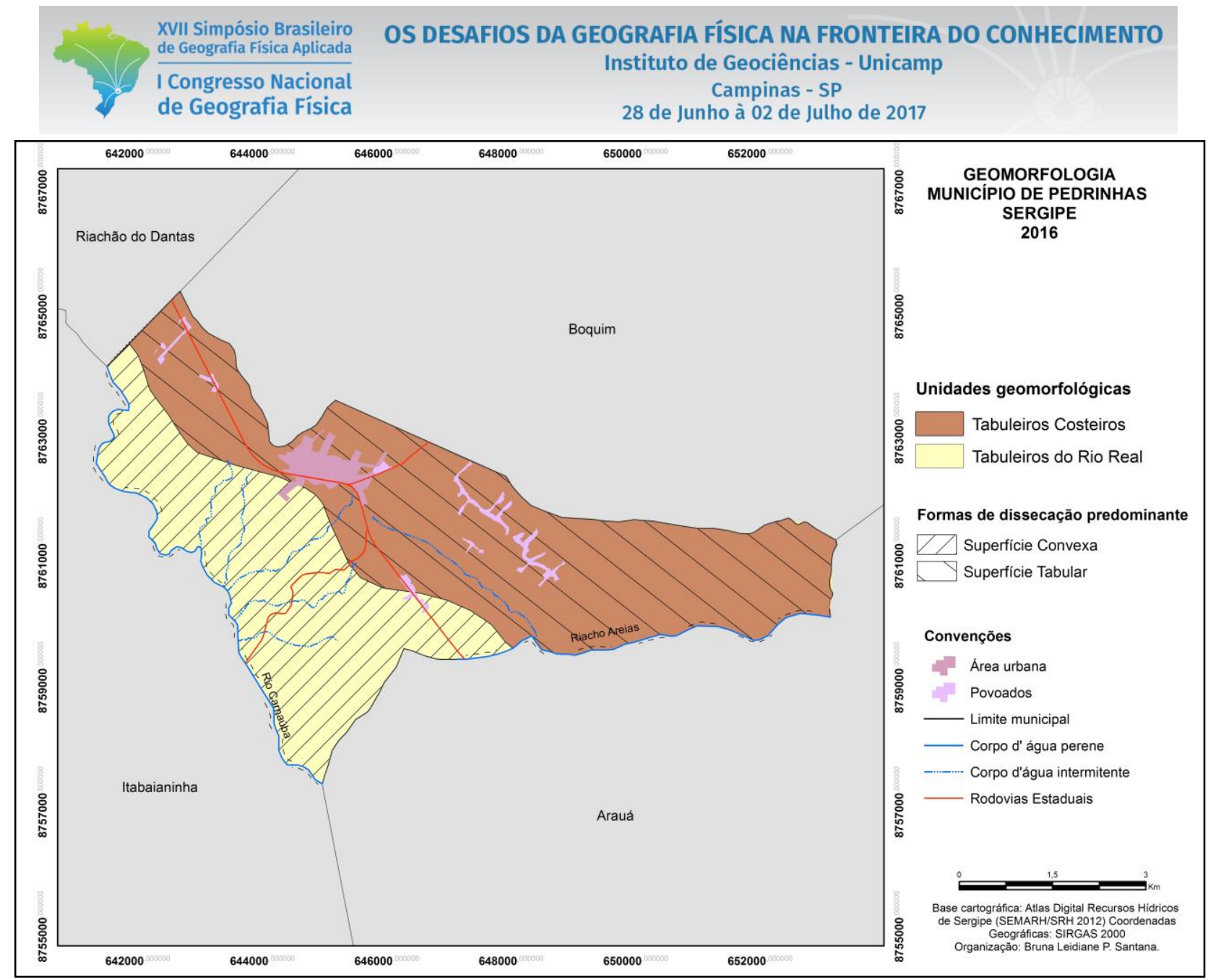

Figura 1 - Unidades geomorfológicas do município de Pedrinhas/SE

$\mathrm{Na}$ unidade dos Tabuleiros do Rio Real o relevo evoluiu sobre o Embasamento Gnáissico do Arqueano/Paleoproterozóico associado ao Complexo Granulítico (SANTOS et al., 2001) formado por um conjunto de litologias - ortognaisses, kinzigitos, rochas calcissilicáticas, metanoritos e biotita gnaisses com alto grau de metamorfismo (CPRM, 2002). Além destes litotipos, a noroeste do município aparecem quartzitos fortemente cristalizados.

Nesta unidade predominam superfícies de dissecação convexa como feições colinares que se assemelham e espigões individualizados partir da instalação da rede de drenagem formada por cursos de água permanentes e intermitentes de vales abertos de fundo chato.

As classes de relevo presente neste modelado varia de plano a ondulado com declividades que se alternam em gradientes de $03 \%$ a 15\%, contudo, prevalece áreas que apresentam maiores declividades (Figura 2). A altimetria do relevo situa-se entre 80 e 180m com exceção de pequenas áreas que podem alcançar até $200 \mathrm{~m}$. 

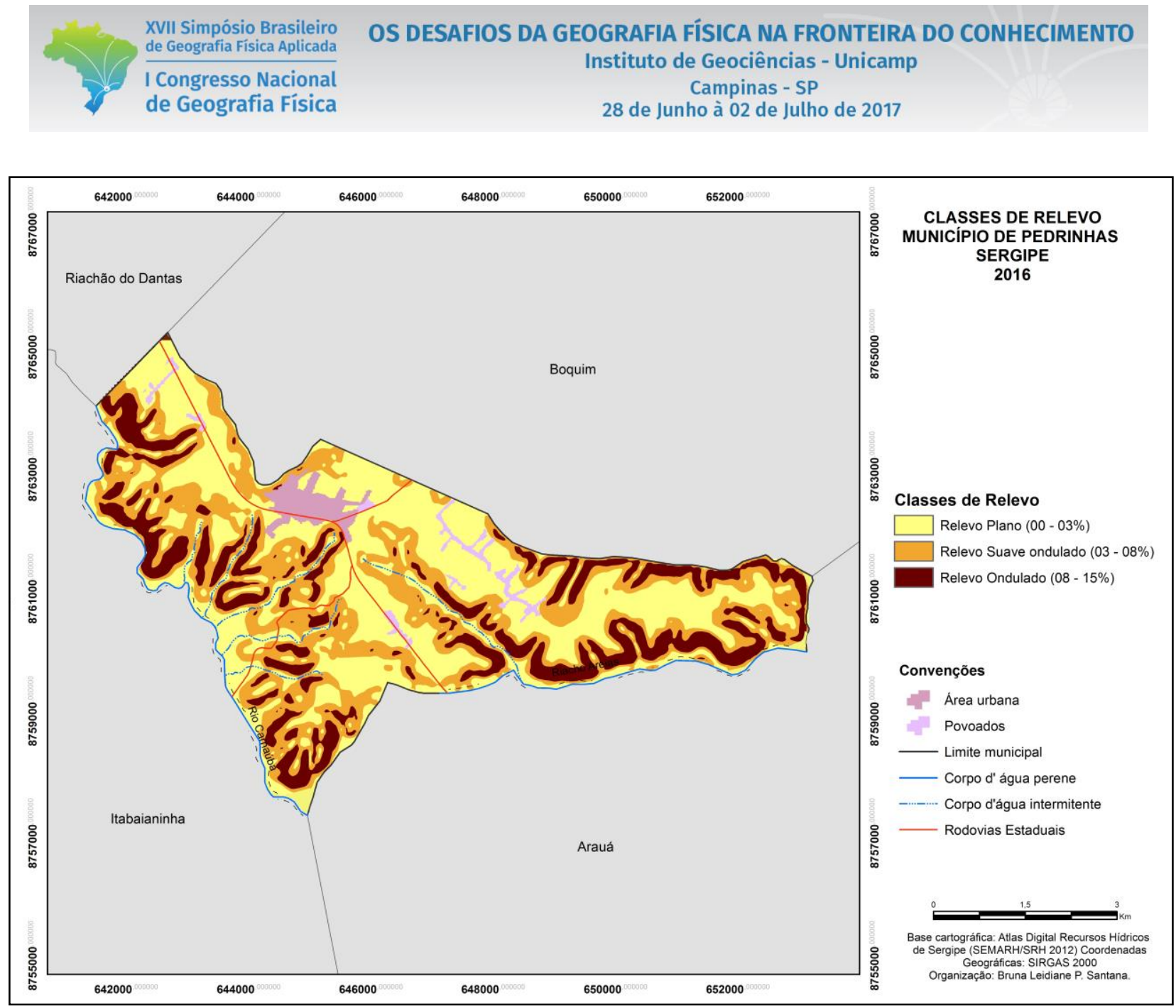

Figura 2 - Classes do relevo município de Pedrinhas/SE

As características geológicas e geomorfológicas referentes a unidade dos Tabuleiros do Rio Real presente no município de Perdinhas contribuíram para a evolução e predomínio do Argissolo Vermelho-Amarelo distrófico e álico que ocorre, principalmente, associado com Argissolo Vermelho-Amarelo eutrófico (BRASIL, 1983), e de forma secundária com Neossolo Fúvico e Neossolo Quartzarênicos.

Na unidade geomorfológica dos Tabuleiros Costeiros a litologia integra as Formações Superficiais Cenozóicas representada pelo Grupo Barreiras, composto por sedimentos terrígenos com gênese [...]"associada a diferentes ciclos de erosão e deposição, por conseguinte, a sucessivas superfícies de aplainamentos, originadas por impulsos tectônicos e climáticos.” (NUNES et al., 2011, p. 20).

A composição litológica do Grupo Barreiras abrange cascalhos, conglomerados, areias finas e grossas e níveis de argila com variada coloração podendo se apresentar inconsolidados e com baixo grau de consolidação facilitando a atuação dos processos erosivos, principalmente em encostas e áreas com intensa atividade antrópica com baixa cobertura vegetal e solos desnudos. 


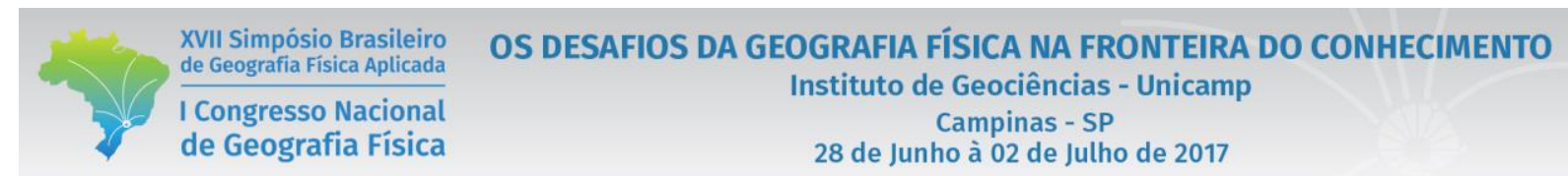

Sobre estas coberturas sedimentares foram esculpidas feições de aplainamento resultantes de dissecação homogênea resultando em interflúvios de topos tabulares com declividade de 3\% que exibem vertentes dissecadas em colinas de topo convexo declividade variáveis entre $8 \%$ a $15 \%$ e cabeceiras de drenagem em forma de anfiteatro decorrente de processos de erosão regressiva. Estas morfologias formam relevo plano e suave ondulado com altitudes que variam entre 80 e 200m (Figura 3).

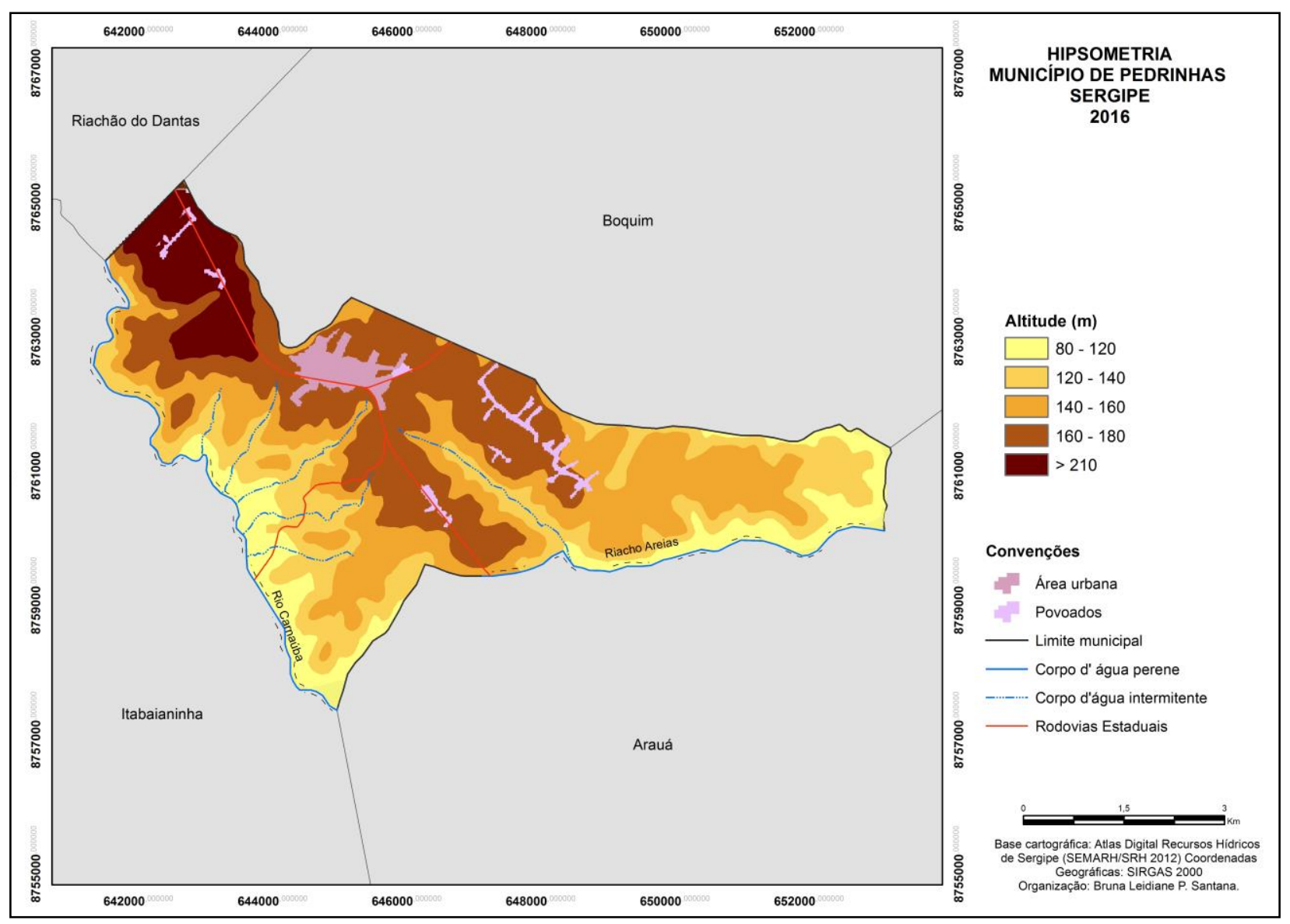

Figura 3 - Hipsometria do município de Pedrinhas/SE

Os solos evoluídos nesta unidade são os Argissolos Vermelho-Amarelo distrófico e Latossolos Amarelos distróficos. O Argissolo Vermelho-Amarelo distrófico apresenta textura arenosa/média e média/argilosa com e sem presença de fragipan que é conceituado como um horizonte subsuperficial, normalmente de textura média e baixo conteúdo de matéria orgânica, apresenta consistência dura a muito dura, podendo adquirir características distintas a depender do grau de umidade, quando seco, encontra-se endurecido e quando úmido, tende a ser quebradiço (EMBRAPA, 1999). 
Os Latossolos Amarelo distrófico são caracterizados como "solos profundos, de coloração amarelada, perfis muito homogêneos, com boa drenagem e baixa fertilidade natural em sua maioria" (EMBRAPA, 2013). Estes solos caracterizam-se pela atuação completa dos processos de latolização ou ferralitização.

\section{O uso e ocupação das terras e processos morfodinâmicos}

No município de Pedrinhas as atividades agrícolas ocupam maior parte do seu território, este fator além de reduzir em apenas 23 ha da área com vegetação nativa, potencializa a atuação da morfodinâmica que tende a foverecer a morfogênese em detrimento da pedogênese. Esta realidade compromete a troca de energia e matéria no sistema geomorfológico podendo gerar feições erosivas que representam a perda de material dos solos que consequentemente pode prejudicar a produção agrícola.

O conjunto de feições morfológicas predominantes na área de estudo é resultado da interação estabelecida entre características geológicas e climáticas. Sobre estas feições se desenvolvem a agricultura permanente e temporária predominante no unidade dos Tabuleiros Costeiros em função da declividade baixa, enquanto e a pecuária extensiva é mais expressiva na unidade dos Tabuleiros do Rio Real que apresenta maiores declividades (Figura 4)

A agricultura permanente é marcada pelo monocultivo de laranja (Citrus sinensis L. Osbeck) que ocorre principalmente nas áreas de baixa declividade como topos de interflúvios e de colinas onde predomina o processo de infiltração e fraca morfodinâmica. Contudo, esta atividade ocupa também vertentes de colinas e de espigões onde o escoamento difuso prevalece com a ocorrência de sulcos incipientes que se instalam em pontos onde a cobertura do solo foi retirada.

A exposição da superfície dos solos à ação das chuvas é maior em função a limpeza do terreno para minimizar a proliferação de espécies invasoras realizada através da capina e da aplicação de herbicidas. Em algumas áreas a exposição do solos faz parte do preparo para a próximo plantação, neste caso, o problema não consiste apenas no tipo de cultivo, mas sim no seu manejo.

Em algumas áreas o sistema produtivo engloba o consórcio de cultivos temporários e permanentes. Geralmente, esta prática ocorre nas entrelinhas e em faixas dos monocultivos evitando a ação direta das águas pluviais sobre os solos.

Nas vertentes das colinas e espigões predomina o cultivo de pastagem que ocupa a maior parte do espaço rural do município de Pedrinhas com gramíneas nativas e cultivadas das espécies Braquiária (Brachiária decumbens) e Pangola (Digitaria decumbens). A produção é diversificada, porém destaca-se a bovicultura de corte. Nestas áreas o grau de proteção dos solos é variável, pois as condições da cobertura variam de 


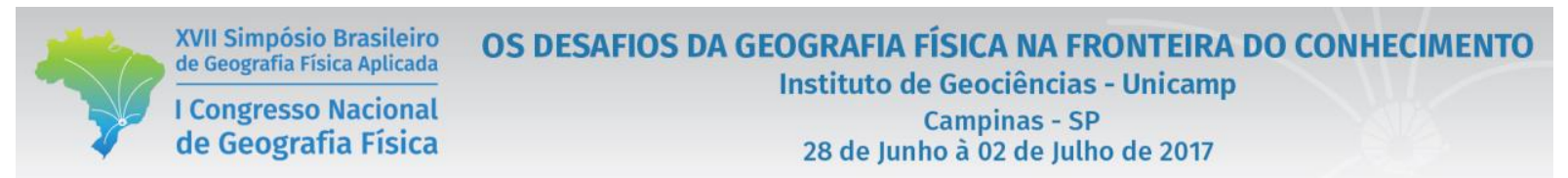

acordo com as características apresentadas pela pastagem associada a regularidade das chuvas e a concentração de animais por área e período.

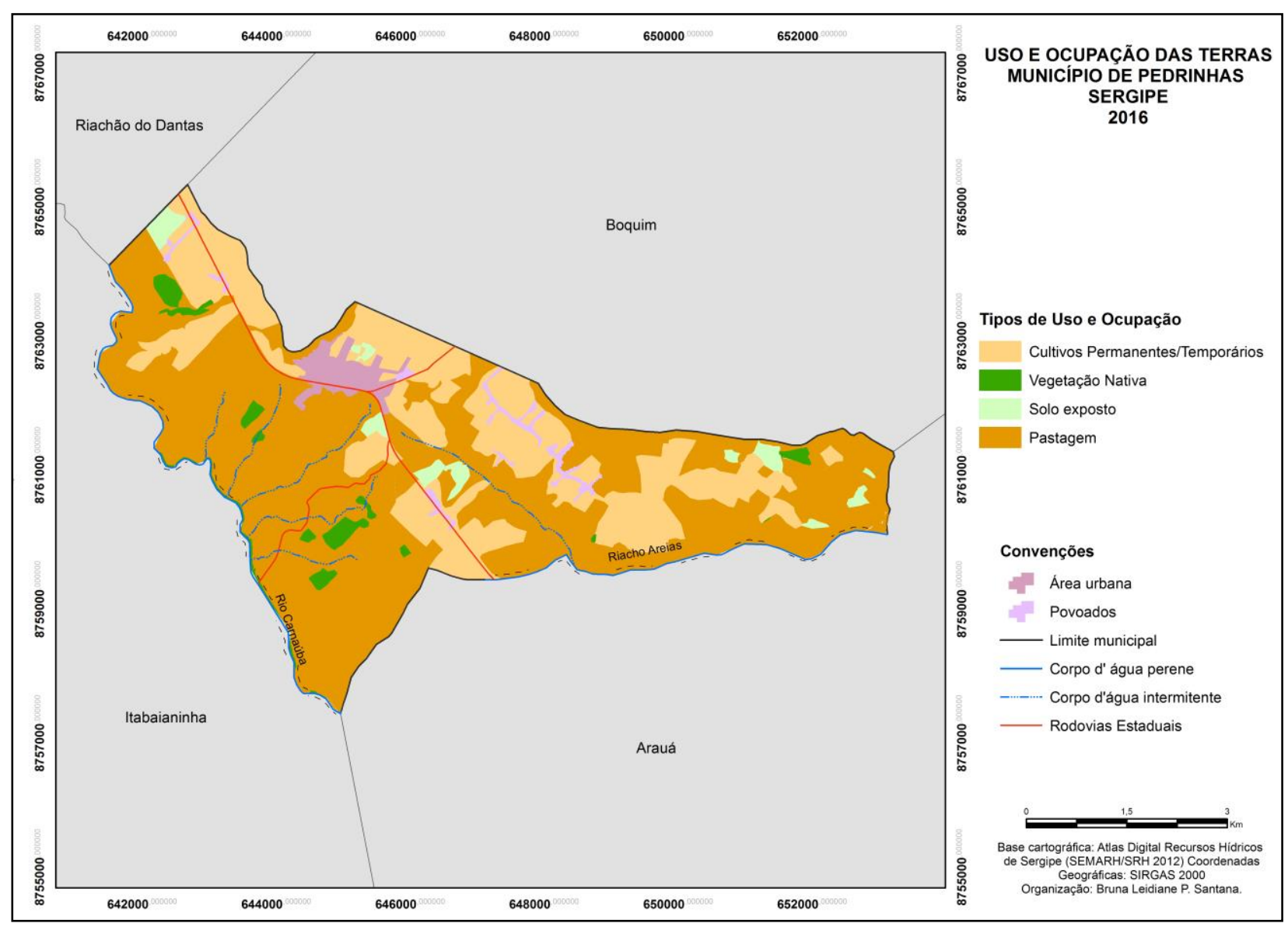

Figura 4 - Uso e ocupação das terras município de Pedrinhas/SE

No verão quando as chuvas apresentam menor volume e a perda de água por evaporação é maior, a regeneração das pastagens é prolongada, implicando na exposição da superfície dos solos à ação pluvial que desagrega suas estruturas removendo partículas pelo fluxo superficial, principalmente de frações granulométricas de menor tamanho e matéria orgânica.

As áreas com maiores declividades como os bordos e as cabeceiras de drenagem e maior número de animais por longos períodos estão sujeitas a intensificação do processo de compactação dos solos e evidenciam feições erosivas de terracetes e sulcos (Figura 4). Além disso, o escoamento superficial concentrado torna-se mais acentuado e a morfodinâmica se intensifica. Contudo, em pontos onde a pastagem apresenta-se conservada estas feições erosivas não se manifestam, levando a inferir que o estado morfodinâmico depende não somente da declividade, mas também do tipo cobertura vegetal e na forma como são manejadas as atividades produtivas. 


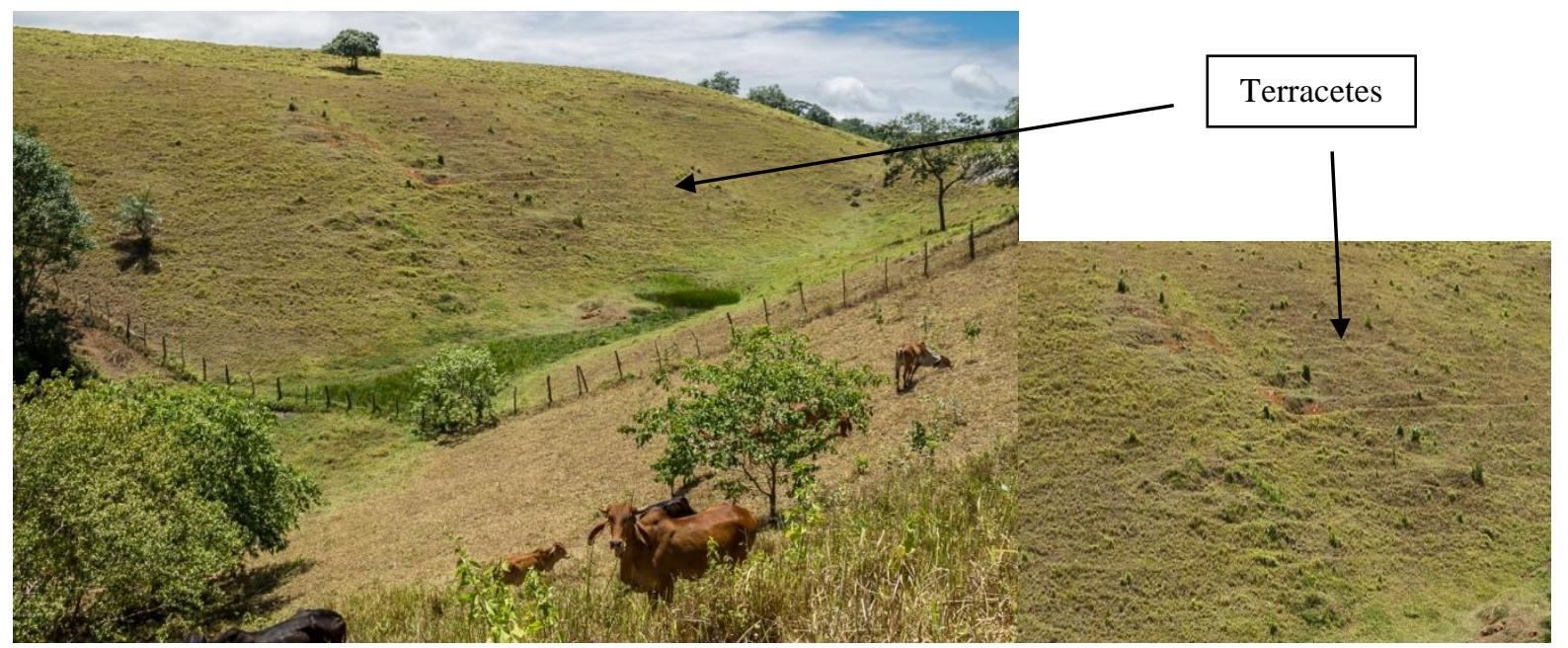

Figura 5 - Terracetes em encosta na unidade geomorfológica do Tabuleiro do Rio Real, município de Pedrinhas/SE

Outro fator de significativa relevância na intensidade da morfodinâmica são os tipos de solos, pois estes apresentam diferentes graus de erodibilidade. Os Argissolos e Latossolos que integram a paisagem do município de Pedrinhas estão mais propícios a erosão do horizonte superficial que remove, além de solo, matéria orgânica e nutrientes em decorrência da sua profundidade e características texturais que varia de média/argilosa à arenosa/média com base nas análises realizadas por Brasil (1983).

Como resultado do uso e ocupação das terras no município de Pedrinhas pelas as atividades agrícolas e agropecuárias tem-se um cenário atual caracterizado pela redução da vegetação nativa, perda de solos através de processos erosivos e assoreamento de canais fluviais que compromete o volume hídrico. A degradação destes recursos poderão se refletir nos aspectos sociais e econômicos, interferindo de forma negativa na qualidade de vida da população, bem como no quantitativo da produção rural.

\section{Conclusão}

Pode-se constatar com a realização deste trabalho, que o município de Pedrimhas apresenta áreas de instabilidade potencial e efetiva em relação aos processos morfodinâmicos. As áreas de instabilidade potencial se manifestam nas feições de baixa declividade como topos dos interflúvios tabular e nas de maior declividade como vertentes das colinas e espigões que apresentem bom estado de conservação da cobertura dos solos. Enquanto as áreas de instabilidade efetiva configuram-se aquelas que estão situadas em encostas com cobertura vegetal descontínua em razão da implantação da pastagem extensiva. 
Diante disso, é necessário que sejam adotadas intervenções mitigadoras dos problemas destacados, como técnicas de manejo que direcionem o uso racional e conservacionista dos solos, principalmente, nas vertentes e encostas, que permitam a regeneração da vegetação nativa nas margens dos cursos de água, nas áreas no entorno das nascentes e dos olhos d'água perenes e bordas dos tabuleiros que constituem área de preservação permanente determinada pela lei $\mathrm{n}^{\circ} 12.651$, de 25 de maio de 2012. $\mathrm{O}$ cumprimento das alternativas propostas contribui para equilíbrio dinâmico das áreas de maior instabilidade.

\section{Bibliografia}

BRASIL. Ministério das Minas e Energia. Projeto RADAMBRASIL: folha SC.24/25 Aracaju/Recife: geologia, geomorfologia, pedologia, vegetação, uso potencial da terra. Rio de Janeiro, 1983. 851 p. (Levantamento de Recursos Naturais, 30).

EMBRAPA. Levantamento de reconhecimento de média intensidade dos solos da região dos tabuleiros Costeiros e da baixada litorânea do estado de Sergipe: folha SC.24-Z-C-III: Boquim. Recife, 1999a. 1 mapa. Escala 1:100.000.

EMBRAPA. Reconhecimento de Solos do Estado de Sergipe: Município de Pedrinhas. Recife, 1983.

EMBRAPA. Sistema brasileiro de classificação de solos. 2. ed. - Rio de Janeiro : EMBRAPA-SPI, 2006.

EMDAGRO. Informações básicas municipais Município de pedrinhas. Sergipe, 2009.

IBGE. Censo agropecuário municipal. Rio de Janeiro, 2010.

NUNES, F. C.; SILVA, E. F. Grupo Barreiras : características, gênese e evidências de neotectonismo. Rio de Janeiro : Embrapa Solos, 2011.

SANTOS, R. A. dos. (Org.). et al. Geologia e recursos minerais do estado de Sergipe: texto explicativo do mapa geológico do estado de Sergipe. Brasília: CPRM; Aracaju: CODISE, 107 p. 1998. (Programa Levantamentos Geológicos Básicos do Brasil). 